\title{
Fustigar os dogmas: Singularidades da critica africana e africanista
}

Sueli Saraiva ${ }^{1}$

RESUMO: Neste texto, propomos fazer algumas considerações sobre o estudo das literaturas africanas contemporâneas, apontando para os desafios postos à crítica voltada para as obras produzidas em Angola e Moçambique, tendo em vista questões como forma, conteúdo, conceitos dogmáticos e cânone.

ABSTRACT: In this text, we will make some considerations on the study of the contemporary African literatures by pointing to the challenges faced by the literary criticism that accounts for works produced in Angola and Mozambique, by approaching subject matters as form, content, dogmatic concepts, and canon.

PALAVRAS-CHAVE: Literatura africana, crítica, forma, conteúdo, cânone. KEYWORDS: African literature, criticism, form, content, canon.

As aves, que aqui gorjeiam, Não gorjeiam como lá. Gonçalves Dias

$\mathrm{O}$ florescimento no século $\mathrm{XX}$ das literaturas angolana $\mathrm{e}$ moçambicana se deu em meio à busca de uma identidade nacional e através de signos que perpassam o colonialismo e a pós-independência, com todos os seus desdobramentos. Essas literaturas, ao refletirem artisticamente tais contextos sócio-históricos, vão revelando o conflito experimentado por essas nações entre o irreversível processo de globalização capitalista e as enraizadas culturas tradicionais, num movimento pendular que tem chamado a atenção da crítica:

\footnotetext{
${ }^{1}$ Mestranda em Estudos Comparados de Literaturas de Língua Portuguesa. Bolsista CAPES. Pesquisa: A atualização do romance nas obras de Boaventura Cardoso e de Mia Couto: A experiência do tempo na narrativa. E-mail: suelisaraiva@usp.br.
} 
[É] chegada a hora de se pensarem algumas postulações sem os clichês dualistas que as recobrem e que não contribuem para o avanço dos estudos literários africanos. Assim, ao invés de atribuir à África apenas o peso da tradição oral e do arcaico, deixando para a Europa o papel da modernidade que se associa naturalmente ao universo da escrita, quero-me debruçar sobre a inter-relação de ambas as coisas. (...) o isto $e$ o aquilo e, não, o isto ou aquilo (Padilha, 2002, p. 39, itálicos da autora).

Os conteúdos oriundos dessa experiência sócio-histórico-cultural apontam para a necessidade de uma forma estética que lhes convenha, conforme o pensamento de Peter Szondi, parafraseado por Iná Camargo: "Todo conteúdo, proveniente da experiência comum, busca a sua forma [e] enquanto o artista não a encontra, tende a adaptar seu conteúdo às formas pré-existentes" (apud Costa, 1998, p. 55). A tendência a adaptar os conteúdos às formas pré-existentes opera na dinâmica do próprio fazer literário, mas, no caso angolano, uma ruptura marcante ocorreu ainda no período da pré-independência (pré-1975) com uma nova forma no plano da narrativa, proposta por José Luandino Vieira. Conforme observa o antropólogo e escritor angolano Ruy Duarte de Carvalho:

Se me parece verdade que com a chamada Geração de 50 o que se verifica sobretudo é uma nítida ruptura ideológica operada no seio das formas literárias correntes na Angola de então, (...) sobretudo com Luandino Vieira, estaremos perante uma franca ruptura em relação à forma (Carvalho, 2003, p. 239).

Essa ruptura formal aponta também para o afastamento da “obsessão da universalidade", ou seja, à tendência de se acreditar "que a literatura africana ganha se se adaptar aos modelos críticos vigentes", conforme advertência de Inocência Mata, que ao referir-se às formas canônicas acrescenta: "Na verdade, esquece-se que tais modelos e formulações se fizeram a partir do cânone literário vigente, sem levar em conta as particularidades de outras literaturas de outros universos culturais e civilizacionais" (Mata, s/d).

Unindo as reflexões de Padilha e Mata, fica clara a necessidade de uma leitura dialética das teorias em voga, formuladas a partir do cânone ocidental, superando a mera adaptação de novos conteúdos às 
formas pré-existentes. Nessa linha de raciocínio, Rita Chaves igualmente escreve sobre o repertório angolano:

Essa produção, ao apropriar-se de outros modelos, impõe-lhe traços da fisionomia que o país vai conquistando. [...] Dialogando também pela diferença com o sistema literário que integra, a literatura [...] vai construindo a sua identidade, uma identidade que recusa a linha dos sentidos únicos e se faz sobretudo a contrapelo (Chaves, 2005, p. 75).

Dessa maneira, o "diálogo pela diferença" e a "recusa da linha dos sentidos únicos", aliados àquele movimento dialético entre "o isto $e$ o aquilo" apontado por Padilha, são parâmetros para o estudo dessas obras literárias através de lentes menos reducionistas. Ou, conforme pressuposto na dialética hegeliana, um movimento de superação caracterizado pela conservação relativa do que foi superado (Aufhebung).

Anatol Rosenfeld, por exemplo, ao teorizar sobre a dissolução da forma do romance e a posição do indivíduo no mundo em transformação do século XX, afirma:

Uma época com todos os valores em transição, e por isso incoerentes, uma realidade que deixou de ser "um mundo explicado", exige adaptações estéticas capazes de incorporar o estado de fluxo e insegurança dentro da própria estrutura da obra (Rosenfeld, 1996, p. 86).

Tal reflexão, ainda que voltada para uma experiência ocidental, é totalmente pertinente à crítica de africanos e africanistas, cujo objeto de análise é um conjunto de valores em transição que, não superando os limites da utopia pós-independência, permanece um mundo inexplicável e distante do prometido "eldorado" globalizado. O jogo dialético tradição vs modernidade, em seu "estado de fluxo e insegurança”, deve ser capturado na estrutura, isto é, na forma das obras literárias.

Para tanto, a crítica deve enfrentar também dilemas conceituais. Ao discorrer sobre a noção de oralidade, um dos eixos de análise das 
literaturas africanas, Ana Mafalda Leite é categórica sobre a "necessidade de apuramento e adequação à nossa área [estudos literários africanos] de alguns conceitos operatórios, como este em questão [oralidade], em termos teóricos e analíticos” (1998, p. 12). Uma vez que a tradição oral é ao mesmo tempo um repositório e parte integrante do conjunto de tradições (crenças, ritos, linhagens etc), ao se buscar "apurar" o conceito "oralidade", deve-se também reposicionar o conjunto de tradições em sua relação com a obra literária.

Nesse sentido, o escritor angolano Boaventura Cardoso, numa entrevista concedida em 2005, ao ser solicitado a comentar sua afirmação de que ele procura "tratar sob o ponto de vista literário, as tradições do povo angolano”, respondeu:

Trata-se aqui da angolanidade iluminada a partir da questão da interação entre a tradição e a modernidade, muito presente em nossa sociedade. (...) Eu sinto que a tradição não é imobilismo total. (...) A própria tradição sofre alterações ao longo dos tempos. (...) A tradição entra no texto enquanto forma e não apenas tema (In Chaves et alii, 2005, p. 31).

A propósito, vale enfatizar que "a tradição não é esse bloco maciço e persistente, viscoso e agarradiço que se imagina e teme quando se projetam as idéias ocidentais de desenvolvimento", retomando as palavras de Ruy Duarte de Carvalho, que prossegue: "Não é um peso, é antes um instrumento de que se serve o dinamismo social para avançar. As estruturas mais sedimentadas (o parentesco, por exemplo) podem revelar-se um instrumento de invenção colectiva” (Carvalho, 2003, p. 175).

Laura Padilha também assina o quadro descrito por Cardoso e Ruy Duarte:

A leitura de uma série expressiva de romances editados nos últimos anos do século passado e nos iniciais do XXI comprova (...) que a tradição ainda permanece sendo um elemento produtor de sentidos dos mais instigantes. Isso se explica pelo fato mesmo de que os sujeitos africanos, nesse tempo marcado pela intensa tempestade da globalização, não abdicam de reforçar o seu próprio repertório cultural (Padilha, s/d). 
Ou ainda nas palavras do moçambicano Lourenço do Rosário, ao analisar o conteúdo do romance $O$ sétimo juramento (2005), de Paulina Chiziane:

O romance consegue (...) trazer à luz da fala e da escrita o que, na realidade, se passa em surdina e que toda a gente sabe e comenta. O mundo do feitiço e dos mitos esteve sempre ligado ao comportamento sociocultural da maior parte dos intervenientes activos na história social de Moçambique, ricos ou pobres, urbanos ou camponeses, instruído ou analfabeto, o moçambicano, de uma forma ou de outra, conhece e, às vezes, enreda-se nele (Rosário, 2007, p. 91).

Ao escrever o prefácio do romance Mãe, materno mar, do já citado Boaventura Cardoso, Carmen Secco argumenta que um dos procedimentos literários do autor insere-se nas "manifestações aparentemente 'mágicas' e 'irracionais' das crenças tradicionais [africanas]”, e explica em nota de rodapé:

O termo ["mágicas"] está entre aspas - como também no título deste prefácio [Entre mar e terra: Uma polifônica viagem pelo universo 'mágico-religioso' de Angola] - porque o que parece 'mágico' e 'fantástico' (categorias de uma crítica européia, ocidental), faz parte do animismo característico de uma visão africana da existência (in Cardoso, 2001, p. 26).

O que nos leva de volta à necessidade de "apuramento" e adequação desse “característico" termo "animismo". Pepetela, num de seus principais romances, Lueji: O nascimento de um império, chegou a propor um certo conceito de "realismo animista" no seguinte diálogo:

(...) Eu queria era fustigar os dogmas, un, deux, foueté, un, deux, trois, quatre, plié...

- Eu sei, Jaime. Por isso te inscreves na corrente do realismo animista...

— É. O azar é que (...) só existe o nome e a realidade da coisa. Mas este bailado todo é realismo animista, duma ponta à outra. Esperemos que os críticos o reconheçam.

(...) O Jaime diz a única estética que nos serve é a do realismo animista (...). Como houve o realismo e o neo, o realismo socialista e o fantástico, e outros realismos por aí. 
(...) isto que andamos a fazer é sem dúvida alguma (Pepetela, 1997, p. 451-456).

Nota-se nessa passagem que o "animismo" é considerado não apenas como tema, ou conteúdo, mas também como forma, na linha proposta por Boaventura Cardoso. No enredo, as personagens de Pepetela são artistas angolanos, também formados na Europa, que se vêem à volta com um balé de temática histórico-africana, cujo título coincide com o do romance: Lueji. O projeto tendo por base as tradições culturais africanas pré-colonização (ritos, danças, guerras etc) quase fracassa, pois um coreógrafo tcheco persistia numa leitura dos ritos e tradições ancestrais numa chave européia.

Transpondo a situação para a análise literária, teríamos as personagens, enquanto membros da sociedade refletida, representando o próprio conteúdo (ao mesmo tempo moderno e tradicional) e, conforme o diálogo acima, colocando a forma (puramente européia) em questão, o que remete ao pensamento de Peter Szondi, "todo conteúdo (...) busca a sua forma...”. As personagens concluíram que o fracasso residia na tentativa de representar um conteúdo repleto de animismos (a história de sua cultura) com o "un, deux, foueté..." da forma clássica do balé. Por fim, o espetáculo só se concretiza, com total sucesso, pela radical mudança formal, incluindo o próprio coreógrafo, coreografia, música e o resto, tudo amparado em uma ampla pesquisa histórica que apontou uma forma adequada à representação artística daquele conteúdo tradicional (ou animista).

A maestria de Pepetela em apresentar metalingüisticamente "o nome e a realidade da coisa" reitera aquela necessidade de colocarmos entre aspas o uso universalista que habitualmente se faz de modelos e formulações cunhados "a partir do cânone literário vigente", conforme a voz já referida de Inocência Mata - a qual é endossada pela resposta de Henrique Abranches, numa entrevista, que, ao ser questionado se concordava com a classificação de elementos de sua obra como “mágicos”, responde recordando Pepetela: 
Eu acho que não está certo. Não é mágico. Mágico tem outras conotações. No cinema e na literatura americana, o mágico é uma pessoa que faz um gesto e outra pessoa aparece com um chapéu alto. Quem deu o melhor nome foi Pepetela. Pepetela chamou a isso uma vez. Disse que eu havia inventado o realismo animista. (...) O que eu faço muitas vezes são estórias à roda de um realismo animista, que é um realismo que anima a natureza. Que, na realidade tradicional, são qualidades animistas. Não são mágicas. Aquilo está baseado em antepassados e em poderes que existem na natureza (Abranches, $\mathrm{s} / \mathrm{d}$ ).

Vemos que o discurso de Pepetela extrapola o campo da ficção, e o apelo à crítica presente em Lueji é explícito: "Esperemos que os críticos o reconheçam" - reconheçam a forma do balé e, concomitante e metalingüisticamente, as características formais do romance. O "realismo animista", nesse exercício de crítica do autor, viria a fustigar, entre outras, as categorias dogmáticas do "realismo maravilhoso", "realismo mágico" e "realismo fantástico". Tais conceitos de origem européia, alguns adotados para as literaturas latino-americanas contemporâneas, têm sido usados por estudiosos para "enquadrar" as obras literárias africanas de teor sobrenatural.

Mas Pepetela, ao abdicar dos adjetivos cabiveis em outras realidades artísticas — o fantástico “e outros realismos por aî” —, chega mesmo a propor um novo adjetivo, uma versão positivada do animismo, um adjetivo que implícita ou explicitamente está presente no contexto social africano e é refletido em suas literaturas.

Ora, dirão alguns, mas se ele está a fustigar dogmas, porque sugerir um conceito, que certamente se tornará dogmático? Arriscamos a conjeturar que o "fustigar" proposto por Pepetela não significa “excluir”, mas “golpear”, “açoitar”, “repreender”, conforme um apanhado das definições que o Houaiss nos legou. Assim, ao postular artisticamente que "a única estética que nos serve é a do realismo animista”, o romance, quiçá, pretende apontar a possibilidade de uma forma artística mais apropriada a um determinado conteúdo, a uma dada realidade, ecoando Szondi e outros teóricos; neste caso, a fustigação dos dogmas significaria "repreender" qualquer conceito 
dogmático levando a reconhecer seus limites e a dar as mãos a uma outra possibilidade (ou quantas forem necessárias).

Para não incorrer em um enfoque redutor, deve-se salientar que as questões aqui colocadas de modo algum sugerem uma ênfase e/ou supervalorização de um conteúdo mítico em detrimento de um complexo social "moderno" mais amplo, que está em construção na realidade africana. A dicotomia aponta antes para "a inter-relação de ambas as coisas”, do moderno e do tradicional, numa síntese literária instigante e, por vezes, esteticamente renovada, como se pode vislumbrar em Lueji, de Pepetela, ou em O sétimo juramento, de Paulina Chiziane.

O exercício de "fustigar os dogmas" é inerente à história literária, daí todos os movimentos de vanguarda, o próprio Modernismo brasileiro, e as contestações de escritores latino-americanos que, ao se depararem com um conteúdo proveniente das culturas indígenas - por exemplo, no Peru e no México - ou das africanas transpostas para Cuba e Haiti, já apontavam para a necessidade de uma outra chave de realização e interpretação artística. Para citarmos um exemplo, o cubano de origem européia Alejo Carpentier, que esteve no Haiti no final dos anos 40, chamou de "realidade maravilhosa" a cultura haitiana refletida em seu romance $O$ reino deste mundo (1949). O escritor afirma no famoso prólogo dessa obra:

Depois de sentir o tão bem propalado sortilégio das terras do Haiti, de ter encontrado as advertências mágicas pelas estradas de Petro e Rada, fui tentado a aproximar aquela maravilhosa realidade recém-vivida à exaustiva pretensão de suscitar o maravilhoso que caracterizou certa literatura européia nestes últimos trinta anos.

Em seguida, Carpentier faz um ataque ao que ele chamou de "o maravilhoso obtido com truques de prestidigitação..." e "fustiga" os métodos de criação da escola surrealista. Eis a conclusão de Carpentier sobre a sua chamada realidade maravilhosa: 
Pela dramática singularidade dos acontecimentos, pela fantástica presença dos personagens [...] - tudo é maravilhoso nessa história impossível de situar na Europa, e que, todavia, é tão real como qualquer feito exemplar daqueles consignados, para edificação pedagógica, nos manuais escolares. Mas o que é a História da América senão toda uma crônica da Realidade Maravilhosa?

Percebe-se que Carpentier não prescindiu totalmente de utilizar a idéia de "fantástico" e "maravilhoso", embora procurasse diferenciar, no caso em questão, o conteúdo constituinte de uma realidade social representada no romance, afastando-o de um conteúdo artístico criado, “inventado". Nesse ponto há semelhança com a proposta de Pepetela, mas o angolano, em sua proposição metalingüística de "realismo animista”, dá um passo adiante, recusando até mesmo a referência aos adjetivos "fantástico" e "maravilhoso".

Reiterando a provocação de Inocência Mata aos que simploriamente acreditam que "a literatura africana ganha se se adaptar aos modelos críticos vigentes", concluímos que um possível ganho, ao nosso ver, poderá advir de uma perspectiva ampliada, que considere a possibilidade de exigência, por um determinado conteúdo, de uma forma de representação artística apropriada, para além dos conceitos canônicos; fustigando dogmas com o olhar voltado para "o isto $e$ o aquilo e, não, o isto ou aquilo", nas sábias palavras de Laura Padilha. Afinal, as aves não gorjeiam da mesma forma em todos os lugares.

\section{Referências bibliográficas}

ABRANCHES, Henrique. "Da mitologia tradicional ao universalismo literário". Entrevista. In União dos Escritores Angolanos (UEA). On-line: www.ueaangola.org/mostra_entrevistas.cfm?ID $=440, \mathrm{~s} / \mathrm{d}$.

CARDOSO, Boaventura. Mãe, materno mar. Porto: Campo das letras, 2001.

CARPENTIER, Alejo. "Prólogo". In: O reino deste mundo. Rio de Janeiro: Civilização Brasileira, 1966.

CARVAlHo, Ruy. Actas da Maianga. Lisboa: Cotovia, 2003.

. "Travessias da oralidade, veredas da modernidade". Palestra conferida em Zurique, Suíça, a partir de texto do próprio autor, novembro de $2003 b$. 
CHAVEs, Rita. Angola e Moçambique: Experiência colonial e territórios literários. Cotia: Ateliê Editorial, 2005.

MATA, Inocência. "Na ciência não pode haver 'nacionalismos' estreitos". Entrevista. In União dos Escritores Angolanos (UEA). On-line: www.ueaangola.org/destaque_entrevistas $1 . \mathrm{cfm} ? \mathrm{ID}=552, \mathrm{~s} / \mathrm{d}$.

Costa, Iná Camargo. Sinta o drama. Petrópolis: Editora Vozes, 1998.

PADILHA, Laura Cavalcante. Novos pactos, outras ficções: ensaios sobre literaturas afro-luso-brasileiras. Porto Alegre: EDIPUCRS, 2002. "A tradição e a transformação em textos romanescos africanos 1". Entrevista. In União dos Escritores Angolanos (UEA). Online www.uea-angola.org/artigo.cfm?ID $=585, \mathrm{~s} / \mathrm{d}$.

PePETEla. Lueji: O Nascimento de um Império. Lisboa: Dom Quixote, $3^{\mathrm{a}}$ edição, 1997.

RosÁRIO, Lourenço. Singularidades II. Cacem: Texto Editores, 2007.

RosenfELD, Anatol. Texto/Contexto I. São Paulo: Perspectiva, 1996.

SECCO, Carmen. "Prólogo". In: CARDOso, Boaventura. Mãe, materno mar. Porto: Campo das letras, 2001.

Szondi, Peter. Teoria do drama moderno: 1880-1950. São Paulo: Cosac \& Naify, 2001. 